\title{
Association between chronic periodontitis and the risk of Alzheimer's disease: a retrospective, population-based, matched- cohort study
}

\author{
Chang-Kai Chen ${ }^{1,2}$, Yung-Tsan Wu ${ }^{3}$ and Yu-Chao Chang ${ }^{1,4^{*}}$ (D)
}

\begin{abstract}
Background: Although recent short-term cross-sectional studies have revealed that chronic periodontitis (CP) may be a risk factor for increased cognitive impairment in patients with Alzheimer's disease (AD), systematic reviews and long-term longitudinal studies have provided less clear evidence regarding the relationship between CP and AD. Therefore, we conducted a retrospective cohort study using the National Health Insurance Research Database (NHIRD) of Taiwan to determine whether patients with CP are at increased risk of developing AD.

Methods: We conducted a retrospective matched-cohort study using the NHIRD of Taiwan. We identified 9291 patients newly diagnosed with CP between 1997 and 2004. A total of 18,672 patients without CP were matched to the patient cohort according to sex, age, index year, co-morbidity and urbanisation level. Cox proportional hazards regression analyses were performed to evaluate the subsequent risk of AD.

Results: Patients with CP had a higher prevalence of hyperlipidaemia, depression, traumatic brain injury and co-morbidities, as well as higher urbanisation levels, than those in the unexposed cohort (all $p<0.01$ ). At the final follow-up, totals of 115 (1.24\%) and 208 (1.11\%) individuals in the CP exposed and unexposed groups, respectively, had developed AD. Patients with 10 years of CP exposure exhibited a higher risk of developing AD than unexposed groups (adjusted HR 1.707, 95\% Cl 1.152-2.528, $p=0.0077$ ).

Conclusions: Our findings demonstrate that 10-year CP exposure was associated with a 1.707-fold increase in the risk of developing AD. These findings highlight the need to prevent progression of periodontal disease and promote healthcare service at the national level.
\end{abstract}

Keywords: Alzheimer's disease, Periodontitis, Risk factors, Nationwide population, Cohort study

\section{Background}

Alzheimer's disease (AD) is a neurodegenerative disease characterised by progressive cognitive decline and memory loss, inevitably leading to complete loss of mental faculties and death [1]. AD is the most common cause of dementia in older adults [2-5]. Furthermore, due to increasing life expectancy and lifestyle changes, recent

\footnotetext{
*Correspondence: cyc@csmu.edu.tw

'School of Dentistry, Chung Shan Medical University, No. 110, Section 1, Jianguo N. Road, Taichung City 40201, Taiwan

${ }^{4}$ Department of Dentistry, Chung Shan Medical University Hospital, Taichung, Taiwan

Full list of author information is available at the end of the article
}

projections have indicated that 1 in 85 individuals will be diagnosed with AD by 2050 [6].

Recent evidence indicates that peripheral infections, blood vessel damage and oxidative stress may aggravate inflammation in the brain and play an important role in the pathogenesis of dementia and $\mathrm{AD}[7,8]$. Indeed, previous reports have revealed that diabetes mellitus [9], hypertension [10], hyperlipidaemia [11], chronic kidney disease [12], depression [13], stroke [14], traumatic brain injury [15] and periodontal problems [16, 17] are associated with cognitive impairment. Chronic periodontitis $(\mathrm{CP})$ is a peripheral infectious/inflammatory condition that is among the leading risk factors for tooth loss [18]. 
$\mathrm{CP}$ has been associated with increases in serum levels of C-reactive protein (CRP) [19] and pro-inflammatory cytokines (e.g., tumour necrosis factor- $\alpha$ ), as well as decreases in anti-inflammatory markers (e.g., interleukin-10) [20]. Studies have further revealed that $\mathrm{CP}$ is linked to numerous inflammatory diseases, including cardiovascular disease [21] and diabetes mellitus [22], as well as to other neurodegenerative disorders, such as Parkinson's disease [23]. Researchers have speculated that this association is due to the increases in systemic inflammation that accompany the growth of periodontal pathogenic microorganisms. In other mechanism by which $\mathrm{CP}$ contributes to $\mathrm{AD}$, systemic inflammation caused by periodontal pathogens may also play a role in vascular disease and endothelial dysfunction. With accumulating studies supporting vascular factors in the development of $\mathrm{AD}$, vascular factors could be a mediator in the development of AD [24-26].

Although recent short-term cross-sectional studies have revealed that $\mathrm{CP}$ may be a risk factor for increased cognitive impairment in patients with $\mathrm{AD}[5,27]$, systematic reviews and long-term longitudinal studies have provided less clear evidence regarding the relationship between $\mathrm{CP}$ and $\mathrm{AD}[1,26,28]$. Therefore, we conducted a retrospective cohort study using the National Health Insurance Research Database (NHIRD) of Taiwan to determine whether patients with $\mathrm{CP}$ are at increased risk of developing $\mathrm{AD}$.

\section{Methods}

\section{Data sources}

Developed in 1995, the National Health Insurance Program provides universal and comprehensive healthcare for approximately $99 \%$ of residents in Taiwan [29]. In the present study, we used 1996-2013 data from the NHIRD in Taiwan. One million individuals included in the NHIRD were selected at random, representing about $4.5 \%$ of all enrolees [30]. There was no significant difference in age or sex between participants included in the study sample and all NHIRD enrolees. We extracted data regarding demographic characteristics, including encrypted identification numbers, sex, dates of birth and death, and diagnostic information. The diagnostic data included the dates of dental procedures, as well as International Classification of Diseases, Ninth Revision, Clinical Modification (ICD-9-CM), diagnostic and procedure codes [31]. Approval for the present study was obtained from the institutional review board (IRB) of Chung Shan Medical University (CS2-15071). The requirement for informed consent was waived by the IRB because all NHIRD data had been de-identified.

\section{Study design and sampled participants}

The present retrospective, matched-cohort study included patients aged $\geq 50$ years who had been newly diagnosed with CP (between 1 January 1997 and 31 December 2004) on the basis of ICD-9-CM diagnostic criteria: code 523.4 (CP) [32]. In addition, each enrolled patient had been diagnosed with $\mathrm{CP}$ following at least two outpatient clinic visits during the 1-year study period [33]. Exclusion criteria were as follows: (1) unknown age and/or sex, (2) diagnosis of $\mathrm{CP}$ prior to 1997 and (3) diagnosis of $\mathrm{AD}$ (ICD-9-CM code 331.0) prior to 1997 or prior to the first visit for CP [33]. To ensure the accuracy of our findings, we also excluded patients with unknown vital status and those who had not used health services in the past 12 months, because the NHIRD does not include death records. The sample included a total of 9291 patients with $\mathrm{CP}$ and 18,672 patients without $\mathrm{CP}$ matched according to sex, age and index years (1:2 ratio).

Both cohorts were followed from the index date until the diagnosis of AD, death or 31 December 2013 (Fig. 1). The covariates included sex and age group (50-59, $60-69$ and $\geq 70$ years). According to the definition of urbanisation issued by the National Institutes of Health in Taiwan, all 365 townships in Taiwan are divided into 7 clusters according to the following variables: population density (people per square kilometre), proportion of the population with a college-level education or higher, proportion of individuals over 65 years old, number of agricultural workers, and number of physicians per 100,000 people. In the present study, townships of one or two clusters, three or four clusters, and five to seven clusters were categorised as levels 1, 2 and 3, respectively [34].

We also analysed AD-related co-morbidities, including hypertension (ICD-9-CM codes 401.1, 401.9, 402.10, 402.90, 404.10, 404.90, 405.1 and 405.9) [10], hyperlipidaemia (ICD-9-CM codes 272.0-272.9) [11], chronic kidney disease (ICD-9-CM codes 580, 581-589, 753, 403, 404, 250.4, 274.1, 440.1, 442.1, 447.3, 572.4, 642.1 and 646.2) [12], depression (ICD-9-CM code 311) [13], stroke (ICD-9-CM codes 433, 434 and 436) [14], diabetes mellitus (ICD-9-CM codes 250-250.3, 250.7) [22] and traumatic brain injury (ICD-9-CM codes 800-804, 850-854, 905.0, 950.1, 950.3, 907.0, 959.01, 959.9, 310.2 and V15.52) [15]. The Charlson comorbidity index (CCI), which contains 17 weighted co-morbidities, was also calculated for each participant [35].

\section{Statistical analysis}

We used $t$ tests and chi-square tests to compare the demographic and clinical characteristics of patients with $\mathrm{CP}$ with those of patients without CP. Univariate and multivariate stratified Cox regression models were then used to calculate HRs and 95\% CIs. Multivariable models were adjusted for AD-related co-morbidities, CCI score, and urbanisation level. The Kaplan-Meier method was used to assess the AD survival probability between the exposed and unexposed cohorts. The log-rank 


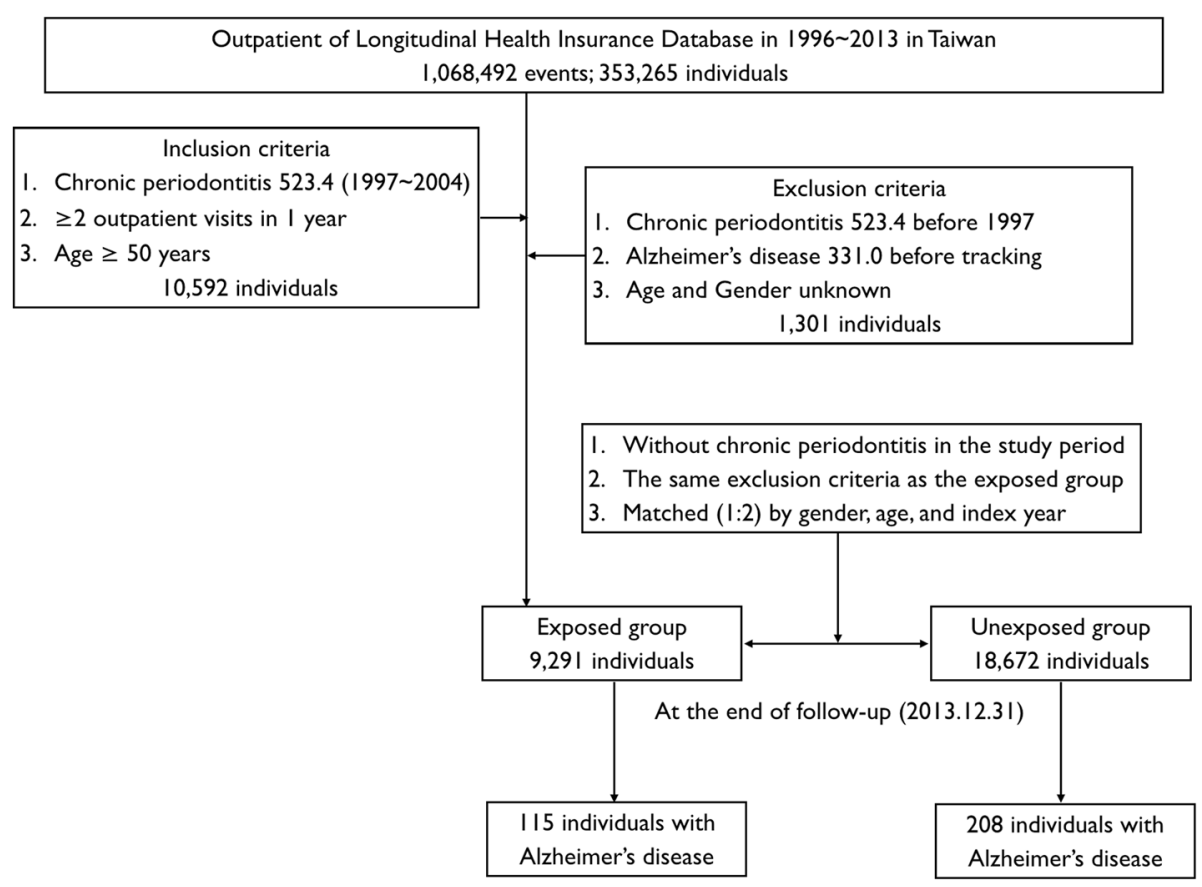

Fig. 1 Flowchart of cohort selection of patients from the National Health Insurance Research Database in Taiwan

test was used to compare differences between these two cohorts.

Sensitivity analysis was performed to identify patients diagnosed with $C P \geq 1$ year following the diagnosis of $\mathrm{AD}$, as well as the incidence of $\mathrm{AD}$ occurring $\geq 10$ years following the diagnosis of CP [4]. To ensure the stability and accuracy of the statistical model, we excluded from the sensitivity analysis patients diagnosed with $\mathrm{AD}<1$ and $<10$ years after the diagnosis of CP [36]. We used a mediation model to identify and explain the other pathways or processes underlying an observed relationship between CP (independent variable) and AD (dependent variable) via the hypothetical mediator of cerebrovascular disease (ICD-9 codes 430-438) [26]. All statistical analyses were performed using SAS version 9.3 (SAS Institute, Cary, NC, USA) and IBM SPSS Statistics version 22 (IBM, Armonk, NY, USA) software. The level of statistical significance was set at $p<0.05$.

\section{Results}

The baseline characteristics of the study sample are presented in Table 1. Patients with CP had a higher prevalence of hyperlipidaemia, depression and traumatic brain injury, as well as a CCI score and urbanisation level, than the unexposed cohort (all $p<0.01$ ). The mean ages and follow-up times for the exposed and unexposed cohorts were $54.1 \pm 10.5$ vs. $54.2 \pm 10.5$ years and $11.9 \pm 2.6$ vs. $12.2 \pm 2.6$ years, respectively.

Totals of 115 (1.24\%) and 208 (1.11\%) patients were diagnosed with $\mathrm{AD}$ in the exposed and unexposed cohorts, respectively (Fig. 1). Table 2 shows the Cox regression analysis of risk factors associated with the development of AD. Although patients with $\mathrm{CP}$ exhibited higher crude HRs (1.301, 95\% CI 1.012-1.673, $p=0.0404)$ for the development of $\mathrm{AD}$ than those without $\mathrm{CP}$, the adjusted $\mathrm{HR}$ was 1.297, indicating a lack of statistical significance (95\% CI 0.995-1.692, $p=0.0547$ ) (Table 2). Patients with depression, stroke and traumatic brain injury tended to have a higher risk for the development of $\mathrm{AD}$ (all $p<0.05$ ). Moreover, the risk of $\mathrm{AD}$ was lower in patients with urbanisation level 2 and level 3 (both $p<0.05)$. Figure 2 depicts the Kaplan-Meier curve for the cumulative risk of $\mathrm{AD}$ in the exposed and unexposed groups. A significant difference was observed between the two groups once 10 years of $\mathrm{CP}$ exposure had been reached ( $p=0.0264$ by log-rank test).

The results of the sensitivity analysis are presented in Table 2. We performed sensitivity analysis after excluding patients diagnosed with $\mathrm{AD}<1$ year and $<10$ years after the diagnosis of $\mathrm{CP}$. The association between $\mathrm{CP}$ and $\mathrm{AD}$ was significant after 10 years of CP exposure (adjusted HR $1.707, p=0.0077)$. In statistics, a mediation model explains and underlies an observed relationship between an independent variable (IV) and dependent variable (DV) via the inclusion of a mediator $(\mathrm{M})$. They have significance of a mediation model (IV $\rightarrow \mathrm{M}, p<0.001,95 \%$ CI 3.292-3.763; $\mathrm{M} \rightarrow \mathrm{DV}, p=0.0118,95 \% \mathrm{CI} 1.121-2.506$; and IV $\rightarrow \mathrm{D}$, $p=0.0077,95 \%$ CI 1.152-2.528). This result shows that cerebrovascular disease is a partial mediator between $\mathrm{CP}$ and $\mathrm{AD}$. $\mathrm{CP}$ can also cause AD directly. 
Table 1 Demographic characteristics of the study cohort at baseline

\begin{tabular}{|c|c|c|c|c|c|c|c|}
\hline \multirow[t]{3}{*}{ Variable } & \multicolumn{2}{|l|}{ Total } & \multicolumn{4}{|c|}{ Chronic periodontitis } & \multirow[t]{3}{*}{$p$ value } \\
\hline & \multirow[b]{2}{*}{$n$} & \multirow[b]{2}{*}{$\%$} & \multicolumn{2}{|l|}{ With } & \multicolumn{2}{|c|}{ Without } & \\
\hline & & & $n$ & $\%$ & $n$ & $\%$ & \\
\hline Total & 27,963 & 100 & 9291 & 100 & 18,672 & 100 & \\
\hline \multicolumn{8}{|l|}{ Sex } \\
\hline Female & 13,119 & 46.92 & 4351 & 46.83 & 8768 & 46.96 & 0.8402 \\
\hline Male & 14,844 & 53.08 & 4940 & 53.17 & 9904 & 53.04 & \\
\hline \multicolumn{8}{|l|}{ Age, years } \\
\hline $50-59$ & 13,947 & 49.88 & 4638 & 49.92 & 9309 & 49.86 & 0.9705 \\
\hline $60-69$ & 8853 & 31.66 & 2945 & 31.70 & 5908 & 31.64 & \\
\hline$\geq 70$ & 5163 & 18.46 & 1708 & 18.38 & 3455 & 18.50 & \\
\hline \multicolumn{8}{|c|}{ Hypertension } \\
\hline No & 6654 & 23.80 & 2251 & 24.23 & 4403 & 23.58 & 0.2314 \\
\hline Yes & 21,309 & 76.20 & 7040 & 75.77 & 14,269 & 76.42 & \\
\hline \multicolumn{8}{|c|}{ Hyperlipidaemia } \\
\hline No & 21,651 & 77.43 & 6935 & 74.64 & 14,716 & 78.81 & $<0.0001$ \\
\hline Yes & 6312 & 22.57 & 2356 & 25.36 & 3956 & 21.19 & \\
\hline \multicolumn{8}{|c|}{ Chronic kidney disease } \\
\hline No & 17,243 & 61.66 & 5697 & 61.32 & 11,546 & 61.84 & 0.4009 \\
\hline Yes & 10,720 & 38.34 & 3594 & 38.68 & 7126 & 38.16 & \\
\hline \multicolumn{8}{|l|}{ Depression } \\
\hline No & 23,283 & 83.26 & 7619 & 82.00 & 15,664 & 83.89 & $<0.0001$ \\
\hline Yes & 4680 & 16.74 & 1672 & 18.00 & 3008 & 16.11 & \\
\hline \multicolumn{8}{|l|}{ Stroke } \\
\hline No & 21,316 & 76.23 & 7081 & 76.21 & 14,235 & 76.24 & 0.9652 \\
\hline Yes & 6647 & 23.77 & 2210 & 23.79 & 4437 & 23.76 & \\
\hline \multicolumn{8}{|c|}{ Diabetes mellitus } \\
\hline No & 14,545 & 52.02 & 4627 & 49.8 & 9918 & 53.12 & $<0.0001$ \\
\hline Yes & 13,418 & 47.98 & 4664 & 50.2 & 8754 & 46.88 & \\
\hline \multicolumn{8}{|c|}{ Traumatic brain injury } \\
\hline No & 22,517 & 80.52 & 7562 & 81.39 & 14,955 & 80.09 & 0.0099 \\
\hline Yes & 5446 & 19.48 & 1729 & 18.61 & 3717 & 19.91 & \\
\hline \multicolumn{8}{|l|}{$\mathrm{CCl}$ score } \\
\hline 0 & 17,032 & 60.91 & 6423 & 69.13 & 10,609 & 56.82 & $<0.0001$ \\
\hline 1 & 7826 & 27.99 & 2206 & 23.74 & 5620 & 30.10 & \\
\hline 2 & 3105 & 11.10 & 662 & 7.13 & 2443 & 13.08 & \\
\hline$\geq 3$ & 1685 & 6.03 & 499 & 5.37 & 1186 & 6.35 & \\
\hline \multicolumn{8}{|c|}{ Urbanisation level } \\
\hline 1 & 2896 & 10.36 & 890 & 9.58 & 2006 & 10.74 & $<0.0001$ \\
\hline 2 & 3675 & 13.14 & 1219 & 13.12 & 2456 & 13.15 & \\
\hline 3 & 19,707 & 70.48 & 6683 & 71.93 & 13,024 & 69.75 & \\
\hline
\end{tabular}

$\mathrm{CCl}$ Charlson comorbidity index

\section{Discussion}

The present study is the first nationwide population-based matched-cohort study to demonstrate that patients with 10-year CP exposure exhibit an increased risk of developing $\mathrm{AD}$ (adjusted HR 1.707), regardless of co-morbidities, CCI score or urbanisation level. The prevalence of $\mathrm{AD}$ significantly increases with age, although AD in general is more common in women than in men [3]. AD is characterised by salient inflammatory features, microglial activation and increased levels of pro-inflammatory cytokines, which contribute to the inflammatory status of the central nervous system [37]. As a low-grade systemic disease, CP may involve the slow release of pro-inflammatory cytokines and CRP into the systemic circulation. This lowgrade inflammation is thought to impact general systemic health and exacerbate other systemic disorders [38]. Therefore, CP may be a significant source of covert peripheral inflammation within the general population. Periodontitis has a tendency to infiltrate the systemic circulation with inflammatory mediators, thereby resulting in systemic disease. Researchers have proposed that periodontitis can lead to progression of AD by further increasing levels of pro-inflammatory cytokines and can lead to the invasion of micro-organisms from the dental plaque biofilm into the brain [28]. Moreover, these proinflammatory cytokines may penetrate the blood-brain barrier and induce neurodegenerative changes that ultimately influence the development of $\mathrm{AD}$ [26]. In the present study, we observed a significant correlation between $\mathrm{CP}$ and $\mathrm{AD}$ only after the 10-year follow-up for the initial diagnosis of CP. This finding supports the notion that pro-inflammatory factors due to CP may slowly and progressively induce neurodegenerative changes that lead to the development of AD. However, further study is required to verify this hypothesis.

In previous small and/or short-term cross-sectional studies, the authors examined only the associations between periodontal inflammation and $\mathrm{AD}$ [5, 27], without investigating the potential cause-and-effect relationship between the two. However, in a previous study, researchers reported that periodontitis is associated with an increased risk of developing dementia [33]. Moreover, a 10 -year clinical observational study conducted by Tzeng et al. revealed that patients with at least 8 years of periodontal problems exhibited a significantly higher risk of developing dementia and neurodegenerative diseases than healthy unexposed groups [4]. Despite these crucial findings, neither of the aforementioned studies identified the role of periodontitis in $\mathrm{AD}$ development. The present population-based study is the first to demonstrate a significantly increased risk of $\mathrm{AD}$ after 10-year $\mathrm{CP}$ exposure. Our findings support the notion that infectious diseases associated with low-grade inflammation, such as $\mathrm{CP}$, may play a substantial role in the pathogenesis of $\mathrm{AD}$ [39]. In 
Table 2 Covariates associated with Alzheimer's disease at end of follow-up with univariate, multivariable and sensitivity analysis of Cox regression analysis

\begin{tabular}{|c|c|c|c|c|c|c|}
\hline \multirow[t]{2}{*}{ Variable } & \multicolumn{3}{|c|}{ Univariate analysis } & \multicolumn{3}{|c|}{ Multivariable analysis } \\
\hline & Crude HR & $95 \% \mathrm{Cl}$ & $p$ value & Adjusted HR & $95 \% \mathrm{Cl}$ & $p$ value \\
\hline \multicolumn{7}{|c|}{ 1-year exclusion in a diagnosis of $A D$} \\
\hline \multicolumn{7}{|c|}{ Chronic periodontitis } \\
\hline Without & Reference & & & Reference & & \\
\hline With & 1.301 & $1.012-1.673$ & 0.0404 & 1.297 & $0.995-1.692$ & 0.0547 \\
\hline \multicolumn{7}{|c|}{ 10-year exclusion in a diagnosis of $A D$} \\
\hline \multicolumn{7}{|c|}{ Chronic periodontitis } \\
\hline Without & Reference & & & Reference & & \\
\hline With & 1.364 & $1.079-1.725$ & 0.0095 & 1.707 & $1.152-2.528$ & 0.0077 \\
\hline
\end{tabular}

$A D$ Alzheimer's disease

The multivariable analyses were adjusted for hypertension, hyperlipidaemia, chronic kidney disease, depression, stroke, traumatic brain injury, diabetes mellitus, Charlson comorbidity index score, urbanisation level

mediation analysis, the role of cerebrovascular disease is as a partial mediator, and CP can also cause AD directly. Systemic inflammation caused by periodontal pathogens, such as Porphyromonas gingivalis and Streptococcus sanguinis, may be a factor in endothelial dysfunction and vascular disease [26]. The mediator model facilitates a better understanding of the relationship between CP and AD. However, it needs more relevant and further investigation to confirm and clarify the pathway.

Co-morbidities including depression, stroke and traumatic brain injury were directly associated with the risk of developing $\mathrm{AD}$ in the present study, in accordance with the findings of previous studies. Burke et al. reported that depression was associated with AD in a group of participants who were initially cognitively asymptomatic [13],

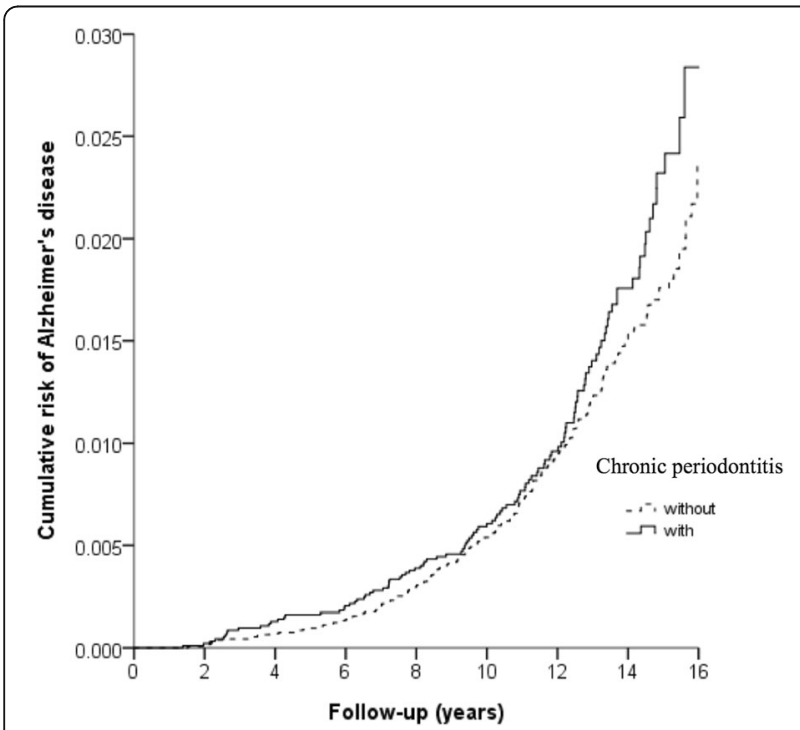

Fig. 2 Kaplan-Meier model based on the Cox-regression analysis with the log-rank test for the cumulative risk of Alzheimer's disease among the exposed and unexposed cohorts whereas additional studies have revealed a significant association between stroke/brain damage and dementia $[14,15]$. Our findings also indicate that urbanisation level 1 was a significant risk factor for $\mathrm{AD}$. This finding may be explained by differences between urban and rural lifestyles, availability of medical resources and convenience of medical access [3, 40]. Patients with AD also exhibit impairments in chewing function due to progressive neurodegeneration, increasing the risk of periodontal problems [41, 42]. Hence, proper dental care and oral rehabilitation are necessary to improve masticatory function in this patient population.

The present study possesses several advantages over previous work. Firstly, we used a nationwide database, which allowed us to examine a large sample of patients over a 16-year follow-up period. Secondly, because the Taiwanese NHIRD provides continued coverage for the whole population of Taiwan and randomises recruits, in the present study, we were able to minimise the influence of bias associated with data collection, region and institution. Thirdly, the use of the NHIRD eliminated the need to minimise patients in the cohort who were lost to follow-up and enabled us to obtain large, geographically dispersed samples of patients with varying sociodemographic characteristics [34]. Lastly, we defined AD using strict criteria (ICD-9-CM code 331.0) to ensure the accuracy of our statistical analysis.

However, the present study also possesses some limitations of note. Firstly, we could not clarify the medical records of all missing recruited $\mathrm{CP}$ and $\mathrm{AD}$ subjects, because all the medical records from the NHIRD were de-identified due to ethical considerations. It is possible that the incidence of $\mathrm{CP}$ or $\mathrm{AD}$ was underestimated in our study because patients who had not received medical records during the study period were excluded. Although this would result in fewer patients with less severe forms of $\mathrm{CP}$ or $\mathrm{AD}$ in our sample, the exposed-unexposed 
matched design would also diminish this bias. Secondly, the nationwide database used in the present study did not allow us to obtain data regarding the severity of AD. Furthermore, $\mathrm{AD}$ and dementia may overlap in this study because we were not able to clarify the medical records of all defined $\mathrm{AD}$, owing to all the medical records from the NHIRD being de-identified due to ethical considerations. Thirdly, the broad age categories are important variable indexes. However, because of this limitation, there may be residual confounding by age [4]. Finally, in detailed demography concerning smoking habits, the NHIRD did not provide personal information regarding certain and definite variables relevant to our research [43]. Moreover, although education is an important variable index of $\mathrm{AD}$, the education level of individuals in the NHIRD is not available. Further research is needed to explain the complex relationship between urbanisation and education.

\section{Conclusions}

Our findings demonstrate that 10-year $\mathrm{CP}$ exposure was associated with a 1.707 -fold increase in the risk of developing AD. These findings highlight the need to prevent progression of periodontal disease and promote healthcare services at the national level.

\section{Abbreviations}

AD: Alzheimer's disease; CCl: Charlson co-morbidity index; CP: Chronic periodontitis; CRP: C-reactive protein; ICD-9-CM: International Classification of Diseases, Ninth Revision, Clinical Modification; IRB: Institutional review board; NHIRD: National Health Insurance Research Database

\section{Acknowledgements}

The authors thank Dr. Jing-Yang Huang, who participated in the design of the research and data interpretation, and they appreciate Yun-Ju Tsai, Li-Heng Chen and Li-Xin Chen for their help in paper collection.

\section{Funding}

Not applicable.

Availability of data and materials

Not applicable.

\section{Authors' contributions}

CKC and YCC conceived of and designed the study. CKC provided administrative support. CKC, YTW and YCC collected and organised data. CKC and YTW analysed and interpreted the data. All authors wrote the manuscript, and all authors read and approved the final manuscript.

\section{Ethics approval and consent to participate}

Approval for the present study was obtained from the institutional review board (IRB) of Chung Shan Medical University (CS2-15071). The requirement for informed consent was waived by the IRB because all NHIRD data had been de-identified.

\section{Consent for publication}

All authors approved the manuscript for submission.

\section{Competing interests}

The authors declare that they have no competing interests.

\section{Publisher's Note}

Springer Nature remains neutral with regard to jurisdictional claims in published maps and institutional affiliations.

\section{Author details}

'School of Dentistry, Chung Shan Medical University, No. 110, Section 1, Jianguo N. Road, Taichung City 40201, Taiwan. ${ }^{2}$ Section of Dentistry, Zuoying Branch of Kaohsiung Armed Forces General Hospital, Kaohsiung, Taiwan. ${ }^{3}$ Department of Physical Medicine and Rehabilitation, Tri-Service General Hospital, School of Medicine, National Defence Medical Centre, Taipei, Taiwan. ${ }^{4}$ Department of Dentistry, Chung Shan Medical University Hospital, Taichung, Taiwan.

Received: 24 April 2017 Accepted: 27 June 2017

Published online: 08 August 2017

\section{References}

1. Gaur S, Agnihotri R. Alzheimer's disease and chronic periodontitis: is there an association? Geriatr Gerontol Int. 2015;15:391-404.

2. Lin RT, Lai CL, Tai CT, Liu CK, Yen YY, Howng SL. Prevalence and subtypes of dementia in southern Taiwan: impact of age, sex, education, and urbanization. J Neurol Sci. 1998;160:67-75.

3. Peng D, Shi Z, Xu J, Shen L, Xiao S, Zhang N, et al. Demographic and clinical characteristics related to cognitive decline in Alzheimer disease in China: a multicenter survey from 2011 to 2014. Medicine (Baltimore). 2016; 95:e3727.

4. Tzeng NS, Chung CH, Yeh CB, Huang RY, Yuh DY, Huang SY, et al. Are chronic periodontitis and gingivitis associated with dementia? A nationwide, retrospective, matched-cohort study in Taiwan. Neuroepidemiology. 2016;47:82-93.

5. Martande SS, Pradeep AR, Singh SP, Kumari M, Suke DK, Raju AP, et al. Periodontal health condition in patients with Alzheimer's disease. Am J Alzheimers Dis Other Demen. 2014;29:498-502.

6. Brookmeyer R, Johnson E, Ziegler-Graham K, Arrighi HM. Forecasting the global burden of Alzheimer's disease. Alzheimers Dement. 2007;3:186-91.

7. Marchesi VT. Alzheimer's dementia begins as a disease of small blood vessels, damaged by oxidative-induced inflammation and dysregulated amyloid metabolism: implications for early detection and therapy. FASEB J. 2011;25:5-13.

8. Tonsekar PP, Jiang SS, Yue G. Periodontal disease, tooth loss and dementia: is there a link? A systematic review. Gerodontology. 2017;34:151-63.

9. Huang CC, Chung CM, Leu HB, Lin LY, Chiu CC, Hsu CY, et al. Diabetes mellitus and the risk of Alzheimer's disease: a nationwide population-based study. PLoS One. 2014;9, e87095.

10. Moreno Cervantes C, Mimenza Alvarado A, Aguilar Navarro S, Alvarado Ávila P, Gutiérrez Gutiérrez L, Juárez Arellano S, et al. Factors associated with mixed dementia vs Alzheimer disease in elderly Mexican adults. Neurologia. 2017;32:309-15.

11. Vanhanen M, Koivisto K, Moilanen L, Helkala EL, Hanninen T, Soininen $H$, et al. Association of metabolic syndrome with Alzheimer disease: a populationbased study. Neurology. 2006;67:843-7.

12. Helmer C, Stengel B, Metzger M, Froissart M, Massy ZA, Tzourio C, et al. Chronic kidney disease, cognitive decline, and incident dementia: the $3 C$ Study. Neurology. 2011;77:2043-51.

13. Burke SL, Maramaldi P, Cadet T, Kukull W. Associations between depression, sleep disturbance, and apolipoprotein E in the development of Alzheimer's disease: dementia. Int Psychogeriatr. 2016;28:1409-24.

14. Huang CY, Li YC, Wang HK, Sung PS, Wang LC, Sun YT, et al. Stroke suggests increased risk of dementia. Curr Alzheimer Res. 2015;12:287-95.

15. Wang HK, Lin SH, Sung PS, Wu MH, Hung KW, Wang LC, et al. Population based study on patients with traumatic brain injury suggests increased risk of dementia. J Neurol Neurosurg Psychiatry. 2012;83:1080-5.

16. Kamer AR, Craig RG, Dasanayake AP, Brys M, Glodzik-Sobanska L, de Leon MJ. Inflammation and Alzheimer's disease: possible role of periodontal diseases. Alzheimers Dement. 2008:4:242-50.

17. Watts A, Crimmins EM, Gatz M. Inflammation as a potential mediator for the association between periodontal disease and Alzheimer's disease. Neuropsychiatr Dis Treat. 2008;:4865-76.

18. Al-Shammari KF, Al-Khabbaz AK, Al-Ansari JM, Neiva R, Wang HL. Risk indicators for tooth loss due to periodontal disease. J Periodontol. 2005;76: 1910-8.

19. Paraskevas S, Huizinga JD, Loos BG. A systematic review and meta-analyses on C-reactive protein in relation to periodontitis. J Clin Periodontol. 2008;35:277-90. 
20. Passoja A, Puijola I, Knuuttila M, Niemelä O, Karttunen R, Raunio T, et al. Serum levels of interleukin-10 and tumour necrosis factor-a in chronic periodontitis. J Clin Periodontol. 2010;37:881-7.

21. Teles R, Wang CY. Mechanisms involved in the association between periodontal diseases and cardiovascular disease. Oral Dis. 2011;17:450-61.

22. Lakschevitz F, Aboodi G, Tenenbaum H, Glogauer M. Diabetes and periodontal diseases: interplay and links. Curr Diabetes Rev. 2011;7:433-9.

23. Liu TC, Sheu JJ, Lin HC, Jensen DA. Increased risk of parkinsonism following chronic periodontitis: a retrospective cohort study. Mov Disord. 2013;28: $1307-8$.

24. Roher AE, Esh C, Kokjohn TA, Kalback W, Luehrs DC, Seward JD, et al. Circle of Willis atherosclerosis is a risk factor for sporadic Alzheimer's disease. Arterioscler Thromb Vasc Biol. 2003;23:2055-62.

25. Honig LS, Kukull W, Mayeux R. Atherosclerosis and AD: analysis of data from the US National Alzheimer's Coordinating Center. Neurology. 2005;64:494-500.

26. Uppoor AS, Lohi HS, Nayak D. Periodontitis and Alzheimer's disease: oral systemic link still on the rise? Gerodontology. 2013;30:239-42.

27. Ide M, Harris M, Stevens A, Sussams R, Hopkins V, Culliford D, et al. Periodontitis and cognitive decline in Alzheimer's disease. PLoS One. 2016; 11, e0151081.

28. Abbayya K, Puthanakar NY, Naduwinmani S, Chidambar YS. Association between periodontitis and Alzheimer's disease. N Am J Med Sci. 2015;7:241-6.

29. Ho Chan WS. Taiwan's healthcare report 2010. EPMA J. 2010;1:563-85.

30. Hsu CC, Wahlqvist ML, Lee MS, Tsai HN. Incidence of dementia is increased in type 2 diabetes and reduced by the use of sulfonylureas and metformin. J Alzheimers Dis. 2011;24:485-93.

31. Romano PS, Roos LL, Jollis JG. Adapting a clinical comorbidity index for use with ICD-9-CM administrative data: differing perspectives. J Clin Epidemiol. 1993:46:1075-9. discussion 1081-90.

32. Gil-Montoya JA, Sanchez-Lara I, Carnero-Pardo C, Fornieles F, Montes J, Vilchez $R$, et al. Is periodontitis a risk factor for cognitive impairment and dementia? A case-control study. J Periodontol. 2015;86:244-53.

33. Lee YT, Lee HC, Hu CJ, Huang LK, Chao SP, Lin CP, et al. Periodontitis as a modifiable risk factor for dementia: a nationwide population-based cohort study. J Am Geriatr Soc. 2017;65:301-5.

34. Liu CY, Hung YT, Chuang YL, Chen YJ, Weng WS, Liu JS, et al. Incorporating development stratification of Taiwan townships into sampling design of large scale health interview survey. J Health Manag (China). 2006;4:1-22.

35. Charlson ME, Pompei P, Ales KL, MacKenzie CR. A new method of classifying prognostic comorbidity in longitudinal studies: development and validation. J Chronic Dis. 1987;40:373-83.

36. Wong CS, Lin YC, Hong LY, Chen TT, Ma HP, Hsu YH, et al. Increased longterm risk of dementia in patients with carbon monoxide poisoning: a population-based study. Medicine (Baltimore). 2016;95:e2549.

37. McGeer PL, McGeer EG. Inflammation, autotoxicity and Alzheimer disease. Neurobiol Aging. 2001;22:799-809.

38. D'Aiuto F, Graziani F, Tete S, Gabriele M, Tonetti MS. Periodontitis: from local infection to systemic diseases. Int J Immunopathol Pharmacol. 2005;18(3 Suppl):1-11.

39. Yan Q, Zhang J, Liu H, Babu-Khan S, Vassar R, Biere AL, et al. Antiinflammatory drug therapy alters $\beta$-amyloid processing and deposition in an animal model of Alzheimer's disease. J Neurosci. 2003;23:7504-9.

40. Llibre Rodriguez JJ, Ferri CP, Acosta D, Guerra M, Huang Y, Jacob KS, et al. Prevalence of dementia in Latin America, India, and China: a populationbased cross-sectional survey. Lancet. 2008;372:464-74.

41. Campos CH, Ribeiro GR, Costa JL, Rodrigues Garcia RC. Correlation of cognitive and masticatory function in Alzheimer's disease. Clin Oral Investig. 2017;21:573-8

42. Campos CH, Ribeiro GR, Stella F, Rodrigues Garcia RC. Mandibular movements and bite force in Alzheimer's disease before and after new denture insertion. J Oral Rehabil. 2017:44:178-86.

43. Wen BW, Tsai CS, Lin CL, Chang YJ, Lee CF, Hsu CH, et al. Cancer risk among gingivitis and periodontitis patients: a nationwide cohort study. QJM. 2014; 107:283-90.

\section{Submit your next manuscript to BioMed Central and we will help you at every step:}

- We accept pre-submission inquiries

- Our selector tool helps you to find the most relevant journal

- We provide round the clock customer support

- Convenient online submission

- Thorough peer review

- Inclusion in PubMed and all major indexing services

- Maximum visibility for your research

Submit your manuscript at www.biomedcentral.com/submit

) Biomed Central 